\title{
Study of Scattering Parameters and Gain of two Longitudinal Slots of Same Electrical Lengths Milled on two Waveguides for Series and Shunt Slot Array Planar Antenna
}

\author{
Hare Ram Jha and Shiva Nand Singh
}

\begin{abstract}
This paper presents a study of two longitudinal slots of same electrical lengths milled on two waveguides for series and shunt slot array planar antenna. Initially single longitudinal slot element is milled on waveguide which is called single element waveguide slot antenna (WSA). Two same or different structures of single element WSA are kept either in series or shunt for making of two element longitudinal waveguide series slot array and shunt slot array planar antenna respectively. Theoretical data for the reflection coefficient and transmission coefficient due to mutual impedance have been obtained for two element series and shunt planar WSA. The theoretical data have been compared with simulated data for validation the proposed design structures. The almost outstanding agreement obtained between the results validates the investigation of proposed design structure. After the reflection and transmission coefficients validation, the total gain of the proposed design structures is simulated. The result found in series slot array planar antenna behaves as a multi band within in X-band for the application of the multi frequency selective device for communication and shunt slot array planar antenna behaves as in single band entire coverage of X-band for the application of long distance data communication.
\end{abstract}

Keywords--- Array, Design, Method of Moments, Multiple Cavity Modeling Technique, Slot, Waveguide

\section{INTRODUCTION}

$\mathrm{S}$ TUDIES on waveguide slot antennas are very common due to their unique features such as lower loss in comparison with micro strip antennas, and simpler structure in comparison with reflector antennas[1], [2]. A large no. of literatures is available in this field. Most of them are about finding the equivalent circuit, resonant length and the radiation pattern of the single isolated slot antenna using different methodologies like variation, transmission line matrix method, Finite Difference Method Time Domain, Method of Moment etc [3]. A few work were

Hare Ram Jha, Research Scholar, Department of Electronics \& Communication Engineering, National Institute of Technology, Jamshedpur, Jharkhand, India.E-mail:hrjha.ece@nitjsr.ac.in

Shiva Nand Singh, Professor, Department of Electronics \& Communication Engineering, National Institute of Technology, Jamshedpur, Jharkhand, India. E-mail:snsingh.ece@nitjsr.ac.in

DOI: 10.9756/BIJRCE.10427 also studied out in two or more than two slot are used as radiated element with mutual coupling for calculating the scattering parameters [4], [5], [6], [7], [8], [9], [10].

A. J. Sangstar et al., [11] employed moment method to analyze a longitudinal slot doublet in both air-filled and dielectric-filled rectangular waveguides, in which the slot radiators are located in the opposing broad faces of the waveguide. Later they also presented an entire domain moment method analysis of an Omni directional linear array antenna [12]. Then after, A. Bastani et al., [13] presented analysis of planar slotted-waveguide array antennas with longitudinal slots using the method of moments. The effects of various mutual couplings, thickness of the waveguide walls, and waveguide proximity were taken into account in this analysis. After two year P. Mondal et al., [14] reported the analysis of an isolated slot doublet in a rectangular waveguide using Magnetic Field Integral Equation (MFIE). The equation was solved using Galerkin specialization of Method of Moment (MOM) and reflection and transmission coefficients were obtained. Equivalent circuit of the waveguide slot doublet was represented on the basis of these coefficients. Later they also presented the design of a linear array antenna having two radiation nulls and otherwise Omni directional radiation pattern using slot doublet. This type of doublet produces two radiation nulls [15]. After four year, Rintu Kumar Gyan et al., [16] paper presented, method of moments based analysis of broad-wall longitudinal slots array antenna using Multiple Cavity Modeling Technique (MCMT) for calculating resonance and scattering parameters two element planar slot array antenna for X-band. Later, they also presented a method of moments based analysis of high-gain broad-band waveguide broad-wall longitudinal slot array antenna for eighteen element slot for calculating scattering parameters and gain for entire coverage of X-band [17]. After that Hare Ram Jha et al., [18] presented a paper design and analysis of waveguide-fed broad-wall longitudinal log periodic slotted array antenna for X-band for calculating the scattering parameters and gain simultaneously. Again, more recently Rintu Kumar Gyan et al., [19] also presented a method of moments based analysis of standard and reduced height a broad-wall longitudinal slot doublets antenna using Multiple Cavity Modeling Technique (MCMT) for single doublet calculating scattering parameters. Above reported literature survey no one author studied the behavior of scattering parameters and gain simultaneously of two element 
series and shunt planar waveguide slot array antenna. So, this is the great opportunity to study on two element series and shunt planar waveguide slot array antenna.

In this paper we have analyzed scattering parameter due to mutual impedance between two slots of same electrical lengths milled on two waveguides, kept side-by-side, keeping their polarization parallel otherwise arbitrarily located. The configuration is shown in Figure 1 (Total 4 configuration).

As the name suggests waveguide slot antenna (WSA) consists with two things slot antenna and waveguide. Any slot has its complementary form in wires or strips, so that the pattern and impedance data of these forms can be used to predict the patterns and impedances of the corresponding slot [20]. Waveguide has been often applied for high power handling capability and low losses [21]. Generally, waveguide is a hollow metallic box that comprises with two broad walls and two narrow walls shown in Figure 2. Slots milled on either the broad wall or on the narrow wall of a rectangular waveguide have found wide application in naval radars. A slot is capable of giving vertical and horizontal polarization, depending on its location and orientation of the broad wall and narrow wall of a rectangular waveguide. Front-fed reflector or Cassegrain antenna systems suffer from the drawback. Moreover, such arrays can be fabricated with minimum power loss compared to the case of reflector antennas. Due to these characteristics the waveguide-fed slots have found an important place in the array antennas as radiating elements.

For design of linear and planar slot arrays, it is first essential to characterize a single slot element. The equivalent
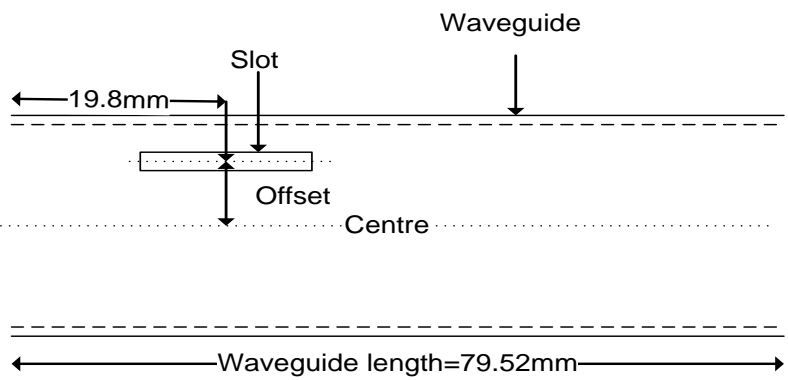

(a)
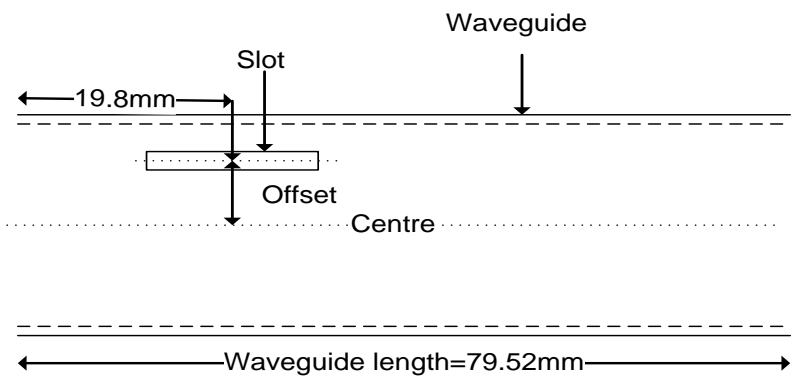

(c) network representation of such element is necessary for designing such arrays. However, when two or more array elements are near to each other, some of the energy that is radiated by one element gets significantly coupled to the other elements. The amount of coupling depends on the radiation characteristics of the elements, separation and orientation between them. This coupling of energy between array elements is known as mutual coupling and in many cases it complicates the analysis and design of antenna. For most practical antenna configuration, mutual coupling is difficult to predict analytically, but must be taken into account because of its significant effects on antenna performance. The effect of mutual coupling performance of an array depends upon the antenna type, its design parameters, relative positioning of the elements, feed and on the scan volume.

Figure 1 represents that a slot is cut on four separate standard waveguide (WR-90) with same electrical lengths. Here, four combinations can be made by Figure 1 (a) \& 1 (b) for case-I: two port two element series slot array planar antenna, Figure 1 (a) \& 1 (d) for case-II: two port two element series slot array planar antenna, Figure 1 (a) \& 1 (c) case-III : four port two element shunt slot array planar antenna, and Figure 1 (b) \& 1 (d) for case-IV: four port two element shunt slot array planar antenna, for measuring the scattering parameters between two slots of same electrical length. Figure 1 (a), 1 (b) and 1 (c) are identical in shape, size and offset position of the slot, but Figure 1 (d) mirror image of Figure 1 (c). The dimension of standard WR-90 waveguide, slot and slot position are shown in Table1.
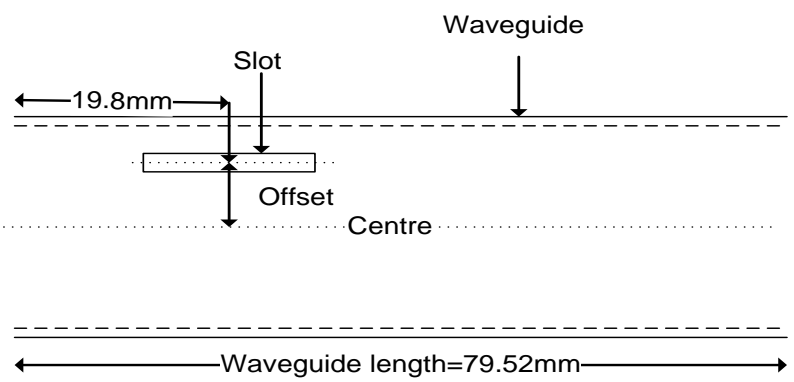

(b)
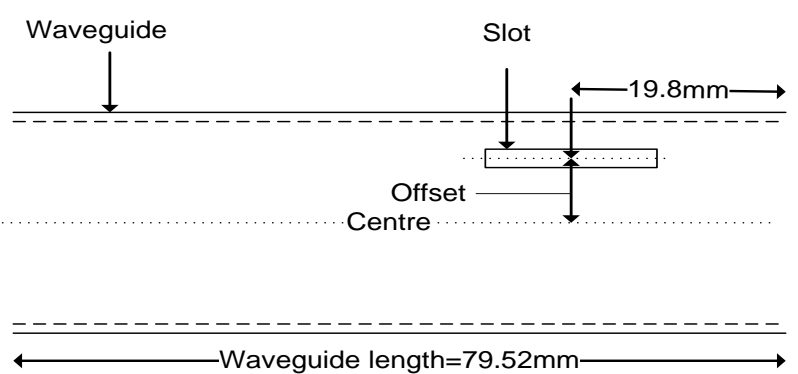

(d)

Figure 1: Configuration of Standard WR-90 Waveguide with Single Slot with slot offset $=-3.5 \mathrm{~mm}$

For design of linear and planar slot arrays, it is first essential to characterize a single slot element. The equivalent network representation of such element is necessary for designing such arrays. However, when two or more array elements are near to each other, some of the energy that is

radiated by one element gets significantly coupled to the other elements. The amount of coupling depends on the radiation characteristics of the elements, separation and orientation between them. This coupling of energy between array elements is known as mutual coupling and in many cases it 
complicates the analysis and design of antenna. For most practical antenna configuration, mutual coupling is difficult to predict analytically, but must be taken into account because of its significant effects on antenna performance. The effect of mutual coupling performance of an array depends upon the antenna type, its design parameters, relative positioning of the elements, feed and on the scan volume.

Figure 1 represents that a slot is cut on four separate standard waveguide (WR-90) with same electrical lengths. Here, four combinations can be made by Figure 1 (a) \& 1 (b) for case-I: two port two element series slot array planar antenna, Figure 1 (a) \& 1 (d) for case-II: two port two element series slot array planar antenna, Figure 1 (a) \& 1 (c) case-III : four port two element shunt slot array planar antenna, and Figure 1 (b) \& 1 (d) for case-IV: four port two element shunt slot array planar antenna, for measuring the scattering parameters between two slots of same electrical length. Figure 1 (a), 1 (b) and 1 (c) are identical in shape, size and offset position of the slot, but Figure 1 (d) mirror image of Figure 1 (c). The dimension of standard WR-90 waveguide, slot and slot position are shown in Table1.

Table 1 : Design Specification of Waveguide Slot Antenna

\begin{tabular}{|c|c|}
\hline Waveguide metal used & $\begin{array}{l}\text { Perfect conductor project metal } \\
\text { (Thickness of metal: } 1.27 \mathrm{~mm} \text { ) }\end{array}$ \\
\hline Wide side wall & $\begin{array}{l}22.86 \mathrm{~mm} \text { (inside measurement) } \\
25.40 \mathrm{~mm} \text { (outer side measurement) }\end{array}$ \\
\hline Short side wall & $\begin{array}{l}10.16 \mathrm{~mm} \text { (inside measurement) } \\
12.70 \mathrm{~mm} \text { (outer side measurement }\end{array}$ \\
\hline Waveguide length & $79.52 \mathrm{~mm}$ (left to right) \\
\hline Figure 1 (a) & \multirow{3}{*}{$\begin{array}{l}\text { Slot length }(2 \mathrm{~L}): 16 \mathrm{~mm} \text {, width }(2 \mathrm{~W}): 1 \mathrm{~mm} \\
\text { Offset: }-3.5 \mathrm{~mm} \text { (from centre to slot centre) } \\
\text { Left to slot distance: } 19.8 \mathrm{~mm} \text { (centre of slot to left plate) }\end{array}$} \\
\hline Figure 1 (b) & \\
\hline Figure 1 (c) & \\
\hline Figure 1 (d) & $\begin{array}{l}\text { Slot length }(2 \mathrm{~L}): 16 \mathrm{~mm} \text {, width }(2 \mathrm{~W}): 1 \mathrm{~mm} \\
\text { Offset: }-3.5 \mathrm{~mm} \text { (from centre to slot centre) } \\
\text { Right to slot distance: } 19.8 \mathrm{~mm} \text { (centre of slot to right plate) }\end{array}$ \\
\hline
\end{tabular}

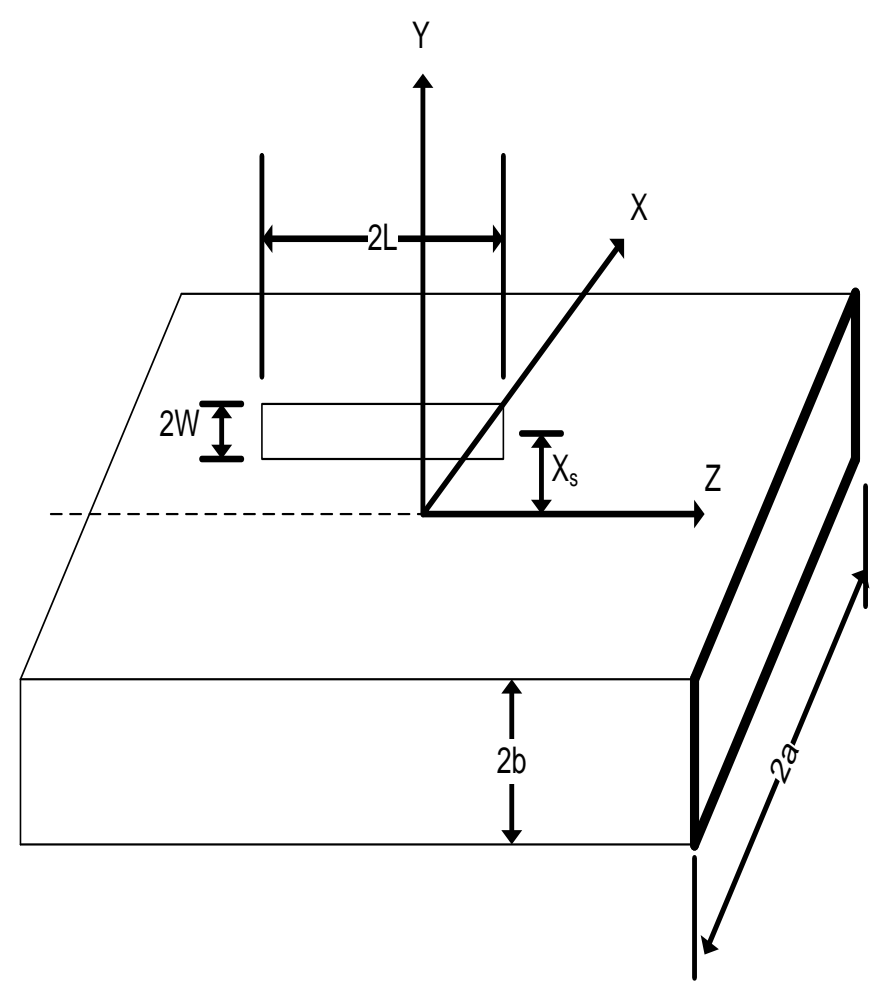

(a)

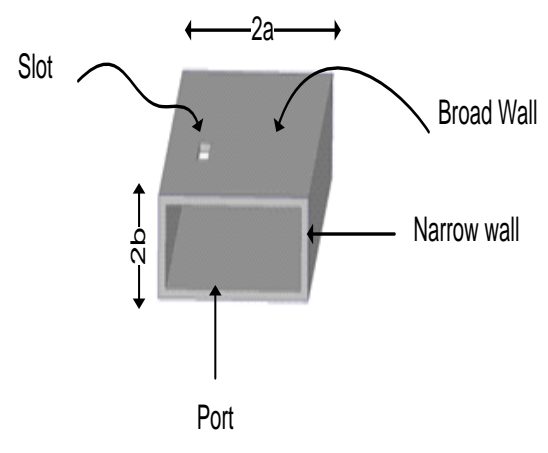

(b)

Figure 2: (a) Design parameter of Longitudinal Slot on the Broad wall of a Rectangular Waveguide, (b) HFSS Design Standard WR-90 Waveguide Milled on a Single Slot (Length " $2 \mathrm{~L} "=16 \mathrm{~mm}$ and Width " $2 \mathrm{~W} "=1 \mathrm{~mm}$ ) with Slot Offset $=-3.5 \mathrm{~mm}$. 
In case-I and case-II both port is excited in Ansoft High Frequency Simulation Structure (HFSS) environment but in case-III and case-IV two ports are excited and rest two ports are connected with matched load. Figure 2 (a) is design of single element longitudinal slot milled on one side broad face of standard waveguide WR-90. Figure 2 (b) is a design view of a single slot waveguide fed antenna.

\section{PROBLEM FoRMULATION}

A. Derivation of the Scattered Field inside a Waveguide due to a Longitudinal Slot on the Broad Wall of the Waveguide

Figure 1(b) shows a longitudinal slot of dimension $2 L \times 2 W$ cut on the broad wall of a rectangular waveguide of cross section $2 a \times 2 b$ and the thickness of the waveguide is $2 \mathrm{t}$. The slot is offset from the broad wall center line by $X_{s}$.

If the slot is narrow, the electric field $\vec{E}_{s}$ existing in the aperture can be approximated as:

$$
\vec{E}_{s}=\hat{u}_{x} E_{x}
$$

and the equivalent magnetic current $\vec{M}_{s}$ is given by:

$$
\vec{M}_{s}=\left\{\begin{array}{c}
\hat{u}_{x} E_{x} \times \hat{u}_{y} \\
\quad=\hat{u}_{z} E_{x} \text { for field radiated into free space } \\
\hat{u}_{x} E_{x} \times\left(-\hat{u}_{y}\right) \\
=-\hat{u}_{z} E_{x} \text { for field scattered into free space }
\end{array}\right.
$$

The electromagnetic field radiated by the slot into the waveguide therefore has to satisfy the scalar Helmholtz equation, with source $\vec{M}_{z}$. In other words,

$$
\nabla^{2} F_{z}+\mathrm{k}^{2} F_{z}=M_{z}
$$

The green's function is defined by the solving of the differential equation (3), The Green's function $G(x, y, z)$ $\left.x^{\prime}, y^{\prime}, z^{\prime}\right)$ is for the electric vector potential function of the internal scattered field due to longitudinal slot on the broad wall of a rectangular waveguide [21].

$$
\begin{aligned}
& G\left(x, y, z / x^{\prime}, y^{\prime}, z^{\prime}\right) \\
& =\sum_{m=0}^{\infty} \sum_{n=0}^{\infty} \frac{\epsilon_{\mathrm{m}} \epsilon_{\mathrm{n}}}{8 \gamma_{m n} a b} \iiint \cos \left\{\frac { m \pi } { 2 a } \left(x^{\prime}\right.\right. \\
& +a)\} \cos \left\{\frac { n \pi } { 2 b } \left(y^{\prime}\right.\right. \\
& +b)\} M_{z}\left(x^{\prime} y^{\prime} z^{\prime}\right) e^{-\gamma_{m n}\left(z-z^{\prime}\right)} d x^{\prime} d y^{\prime} d z^{\prime}
\end{aligned}
$$

\section{B. Derivation of reflection Coefficient and Transmission coefficient formula using Multiple Cavity Modeling Technique (MCMT)}

Figure 1 (a) and 1 (b) are kept side-by-side in the series, ultimately combined make a new structure two element series slot array planar antenna, considered case-I for two element longitudinal slot array waveguide fed antenna. Figure 1 (a) and 1 (d) kept side-by-side in series; at last combined make a new structure two element series slot array planar antenna that reformed case-II for two element longitudinal slot array waveguide fed antenna. Figure 1 (a) and 1 (c) kept side-byside in shunt, ultimately combined make a new structure two element shunt slot array planar antenna, which is considered as a case-III for two element longitudinal slot array waveguide fed antenna. Figure 1 (b) and 1 (d) kept side-byside in shunt, ultimately combined make a new structure two element shunt slot array planar antenna, that is performed case-IV for two element longitudinal slot array waveguide fed antenna.

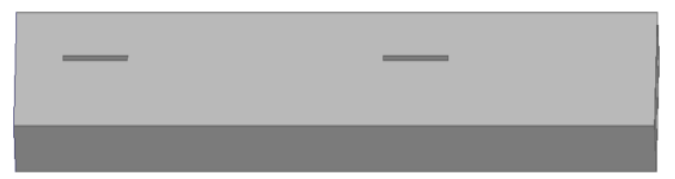

Figure 3: Combine Figure 1 (a) and 1 (b) antenna, kept sideby-side in series with the help of HFSS of two longitudinal slots of same electrical lengths milled on two waveguides for series slot array planar antenna.

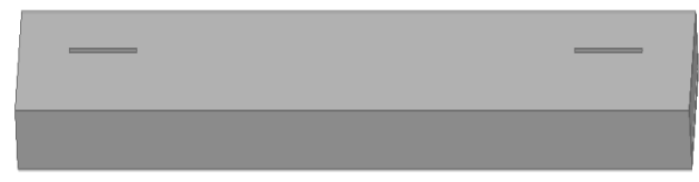

Figure 4: Combine Figure 1 (a) and 1 (d) antenna, kept sideby-side in series with the help of HFSS, of two longitudinal slots of same electrical lengths milled on two waveguides for series slot array planar antenna.

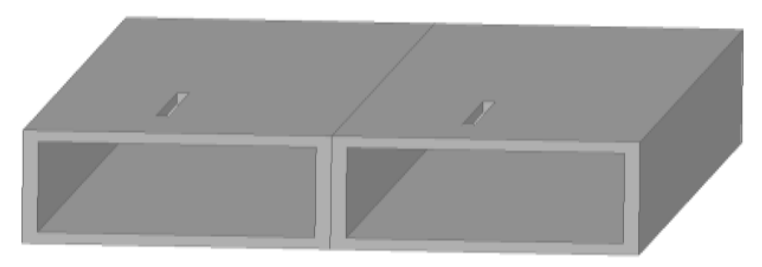

Figure 5: Combine Figure 1 (a) and 1 (c) antenna, kept sideby-side in parallel with the help of HFSS of two longitudinal slots of same electrical lengths milled on two waveguides for shunt slot array planar antenna.

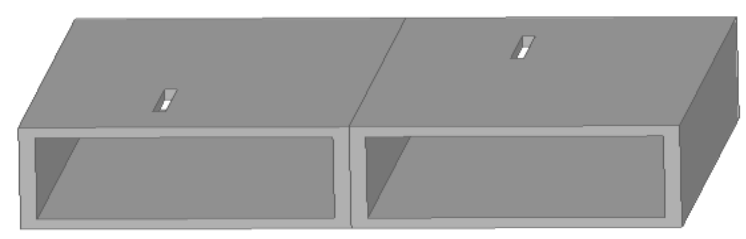

Figure 6: Combine Figure 1 (b) and 1 (d) antenna, kept sideby-side in parallel with the help of HFSS of two longitudinal slots of same electrical lengths milled on two waveguides for shunt slot array planar antenna.

The 3D view of a waveguide fed planar two element broad-wall longitudinal slot array antenna for case- I, case -II, case-III, and case-IV are shown in Figure 3, Figure 4, Figure 5, and Figure 6 respectively. Whereas the top view of the waveguide slot antenna is shown in Figure 7. The corresponding cavity modeling and details of magnetic current 
at the apertures is shown in Figure 8.

The electric field at the slot may be assumed to be Xdirected can be expressed in terms of a sum of weighted sinusoidal basis function $e_{p, z}^{i}$ defined over the entire length of the slot as follows:

$$
\vec{E}^{i}\left(x^{\prime}, y^{\prime}, z^{\prime}\right)=\hat{u}_{x} \sum_{\mathrm{p}=1}^{\mathrm{M}} \mathrm{E}_{\mathrm{p}, \mathrm{z}}^{\mathrm{i}} \mathrm{e}_{\mathrm{p}, \mathrm{z}}^{\mathrm{i}}
$$

Where, $e_{p, z}^{i}$ is defined as:

$$
\begin{aligned}
& \mathrm{e}_{\mathrm{p}, \mathrm{z}}^{\mathrm{i}}\left(x^{\prime}, y^{\prime}, z^{\prime}\right) \\
& =\left\{\begin{array}{cr}
\sin \left\{\frac{p \pi}{2 l}\left(z^{\prime}-W_{i}+L_{i}\right)\right\} \delta\left(y^{\prime}-b\right) & \text { on aperture } " i^{\prime \prime} \\
0 & \text { Elsewhere }
\end{array}\right.
\end{aligned}
$$

Where, " $2 \mathrm{~L}_{\mathrm{i}}$ " the length of the $\mathrm{i}^{\text {th }}$ slot, " $2 \mathrm{~b}$ " the guide height, and $\mathrm{Z}_{\mathrm{i}}$ the offset of the $\mathrm{i}^{\text {th }}$ slot along the $\mathrm{z}$-direction of propagation distance

It is seen from the above expression for the electric field, that the field exists only in the $y=b$ plane, and that is no variation of the electric field in the $\mathrm{x}$-direction, i.e. in the direction of the slot width.

The equivalent magnetic current for computing the externally scattered field is obtained using equation (2) as follows:

$$
\vec{M}_{e}=E^{i}\left(x^{\prime}, y^{\prime}, z^{\prime}\right) \times \hat{u}_{y}=\hat{u}_{z} \sum_{\mathrm{p}=1}^{\mathrm{M}} \mathrm{E}_{\mathrm{p}, \mathrm{z}}^{\mathrm{i}} \mathrm{e}_{\mathrm{p}, \mathrm{z}}^{\mathrm{i}}
$$

In the region of the slot, $\mathrm{z}$-component of the magnetic field $H_{z}^{w v g}$ is related to the $F_{z}$ as follows:

$$
H_{z}^{w v g}=\frac{1}{j k \eta}\left(k^{2}+\frac{\partial^{2}}{\partial z^{2}}\right) F_{z}
$$

And that for the evaluation of the internally scattered field is:

$$
\vec{M}_{i}=E^{i}\left(x^{\prime}, y^{\prime}, z^{\prime}\right) \times\left(-\hat{u}_{y}\right)=\hat{u}_{z} \sum_{\mathrm{p}=1}^{\mathrm{M}} \mathrm{E}_{\mathrm{p}, \mathrm{z}}^{\mathrm{i}} \mathrm{e}_{\mathrm{p}, \mathrm{z}}^{\mathrm{i}}
$$

With respect to the cavity and free space coordinate the aperture is centered and hence $x_{s}=0$ in the expression of $\mathrm{e}_{\mathrm{p}, \mathrm{z}}^{\mathrm{i}}$. For the dominant mode $\mathrm{TE}_{10}$ mode excitation in the waveguide, the incident $y$-directed electric field can be described as:

$$
\begin{aligned}
& \mathrm{E}_{\mathrm{y}}^{\mathrm{inc}} \propto\left(\frac{\pi \mathrm{x}}{2 \mathrm{a}}\right) \mathrm{e}^{-\mathrm{j} \beta z} \\
& H_{z}^{i n c}=-\frac{1}{j k \eta} \frac{\partial E_{y}}{\partial x}
\end{aligned}
$$

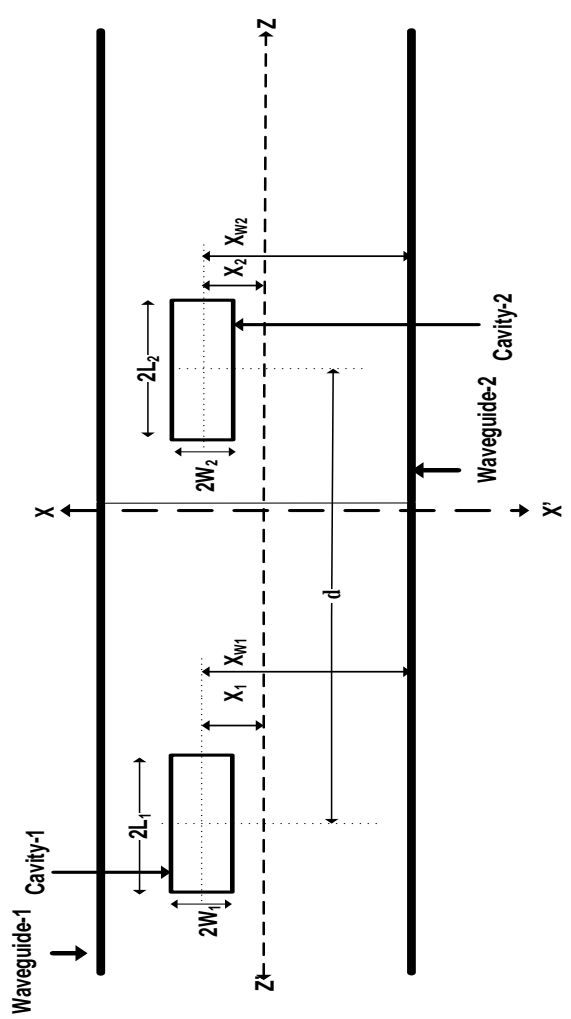

(a)

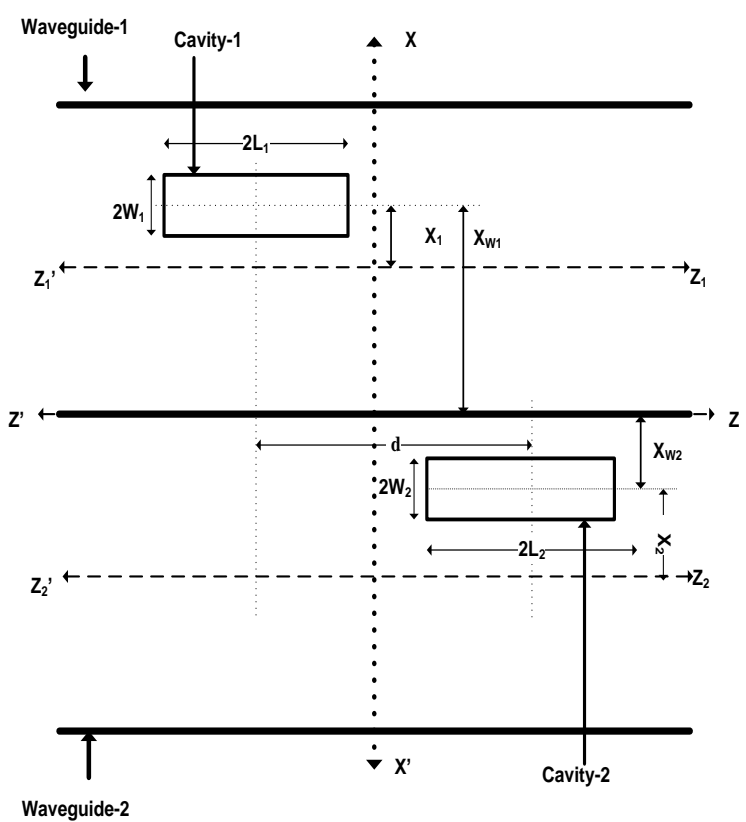

(b)

Figure 7: Top view of two element slot array with (a) series connection and (b) shunt connection of planar waveguide slot antenna for two waveguides 


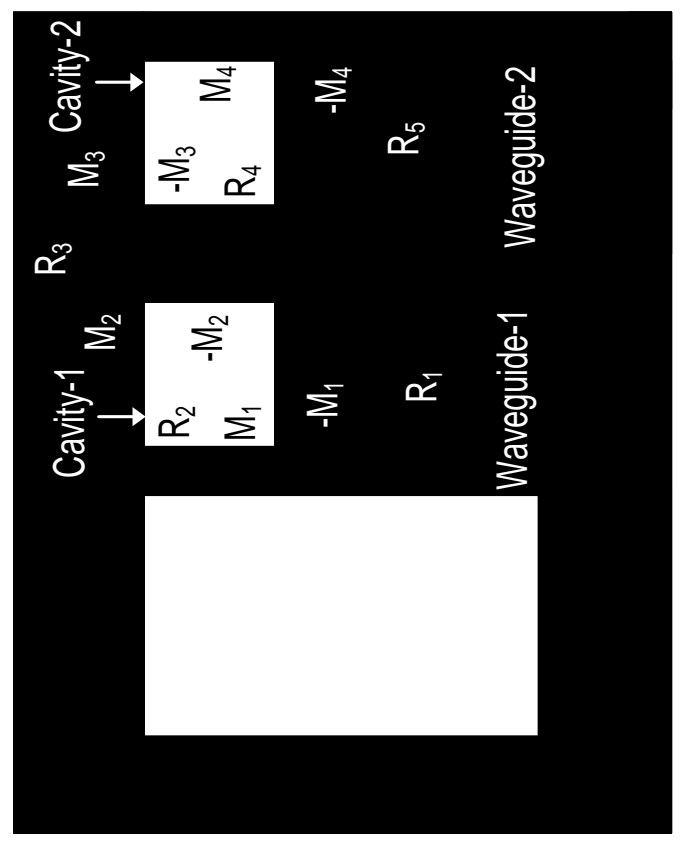

(a)

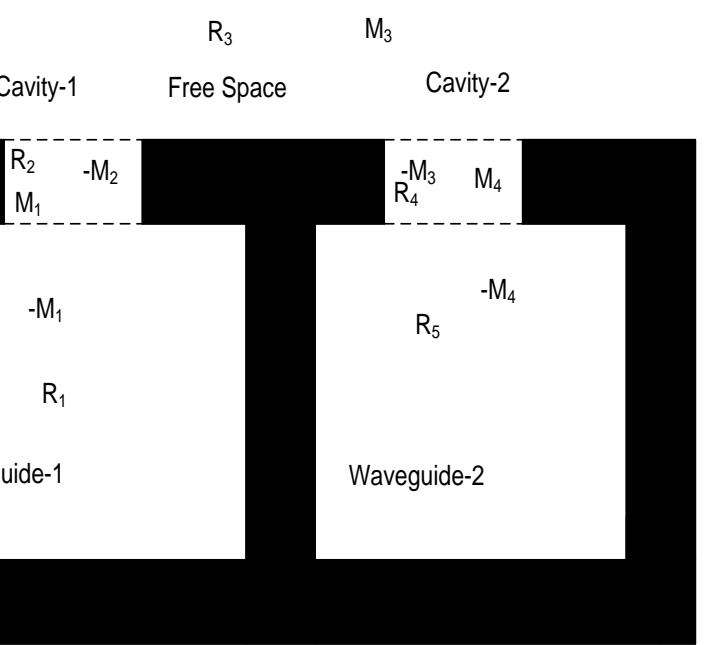

(b)

Figure 8: Details of different regions and magnetic currents at the apertures of two element planar waveguide slot antenna for (a) series connection (b) shunt connection for two waveguides.

Since from the analysis, the incident electric field can be assumed to be of any strength. For the sake of convenience, we may assume the $\mathrm{z}$ component of incident magnetic field to be:

$$
H_{z}^{i n c}=-j \sin \left(\frac{\pi x}{2 a}\right) e^{-j \beta z}
$$

Using equivalence principle, electric field distribution the fictitious magnetic currents existing at apertures can be obtained. For the proposed structure, the tangential components of magnetic field existing at different regions can be expanded as:

Region $1\left(R_{1}\right): H_{z}^{\text {wvg } 1}\left(-M_{z}^{1}\right)+H_{z}^{\text {inc }}$

$$
\begin{aligned}
& \operatorname{Region} 2\left(R_{2}\right): H_{z}^{\text {cav } 1}\left(M_{z}^{1}\right)+H_{z}^{\text {cav } 1}\left(-M_{z}^{2}\right) \\
& \text { Region } 3\left(R_{3}\right): H_{z}^{\text {ext }}\left(M_{z}^{2}\right)+H_{z}^{\text {ext }}\left(M_{z}^{3}\right) \\
& \text { Region } 4\left(R_{4}\right): H_{z}^{\text {cav } 2}\left(-M_{z}^{3}\right)+H_{z}^{\text {cav } 2}\left(M_{z}^{4}\right) \\
& \text { Region } 5\left(R_{5}\right): H_{z}^{\text {wvg } 2}\left(-M_{z}^{4}\right)
\end{aligned}
$$

In the region of the slot, the tangential components of the magnetic field should be continuous, which results in the following boundary conditions:

Aperture 1 (Region 1 = Region 2):

$$
H_{z}^{w v g 1}\left(M_{z}^{1}\right)+H_{z}^{\operatorname{cav} 1}\left(M_{Z}^{1}\right)-H_{z}^{\operatorname{cav} 1}\left(M_{z}^{2}\right)-H_{z}^{i n c}=0
$$

Aperture 2 (Region $2=$ Region 3):

$$
-H_{Z}^{\text {cav } 1}\left(M_{Z}^{1}\right)+H_{Z}^{\text {cav } 1}\left(M_{Z}^{2}\right)+H_{Z}^{\text {ext }}\left(M_{Z}^{2}\right)+H_{Z}^{\text {ext }}=0
$$

Aperture3 (Region 3 = Region 4):

$$
\begin{aligned}
& H_{Z}^{\text {ext }}\left(M_{Z}^{2}\right)+H_{Z}^{\text {ext }}\left(M_{z}^{3}\right)-H_{Z}^{\text {cav } 2}\left(M_{z}^{3}\right)+H_{Z}^{\text {cav } 2}\left(M_{Z}^{4}\right) \\
& =0
\end{aligned}
$$

Aperture4 (Region4=Region5):

$$
H_{z}^{\text {cav } 2}\left(M_{z}^{3}\right)+H_{z}^{\text {cav } 2}\left(-M_{z}^{4}\right)+H_{z}^{w v g 2}\left(M_{z}^{4}\right)=0
$$

The field components of the equation (18) - (21) are given by [22]:

$$
\begin{array}{r}
H_{z}^{\text {ext }}\left(M_{z}^{i}\right)=\frac{\mathrm{W}_{\mathrm{i}} \mathrm{L}_{\mathrm{i}}}{\eta \kappa \pi^{2}} \sum_{\mathrm{p}=0}^{\mathrm{M}} E_{p, z}^{i} \int_{-\infty}^{\infty} \int_{-\infty}^{\infty} \frac{\kappa^{2}-\kappa_{\mathrm{x}}^{2}}{\left(\kappa^{2}-\kappa_{\mathrm{x}}^{2}-\kappa_{\mathrm{z}}^{2}\right)^{\frac{1}{2}}} \\
. \operatorname{sinc}\left(\kappa_{\mathrm{x}} \mathrm{W}_{\mathrm{i}}\right) \mathrm{e}^{-j\left(\kappa_{\mathrm{x}} \mathrm{x} 1+\kappa_{\mathrm{z}} \mathrm{z} 1\right)}\left[\frac{\left\{\begin{array}{l}
j \sin \left(\kappa_{\mathrm{z}} \mathrm{L}_{\mathrm{i}}\right) \text { if } \mathrm{p} \text { is even } \\
\cos \left(\kappa_{\mathrm{z}} \mathrm{L}_{\mathrm{i}}\right) \text { if } \mathrm{p} \text { is odd }
\end{array}\right.}{\frac{\mathrm{p} \pi}{2}\left\{1-\left(\frac{2 \mathrm{~L}_{\mathrm{i}} \mathrm{k}_{\mathrm{z}}}{\mathrm{p}}\right)\right\}}\right]
\end{array}
$$

$$
\begin{aligned}
& H_{Z}^{w v g}\left(M_{Z}^{i}\right) \\
& =-\sum_{p=1}^{M} E_{p, z}^{i} \sum_{m=0}^{\infty} \sum_{n=0}^{\infty} \frac{j \epsilon_{m} \in_{n} W_{i}}{2 \eta \kappa \gamma_{\mathrm{mn}}^{2}} \frac{\cos (n \pi)}{1+S^{2}(p)} \cos \left\{\frac { m \pi } { 2 a } \left(x_{i}\right.\right. \\
& +a)\} \sin c\left\{\frac{m \pi}{2 a} W_{i}\right\} \cos \left\{\frac{m \pi}{2 a}(x+a)\right\}\left[\left\{k^{2}\right.\right. \\
& \left.-\left(\frac{\mathrm{p} \pi}{\mathrm{L}_{\mathrm{i}}}\right)\right\} \sin \left\{\left(\frac{\mathrm{p} \pi}{\mathrm{L}_{\mathrm{i}}}\right)\left(z+L_{i}\right)\right\}\left(\kappa^{2}\right. \\
& \left.+\gamma_{\mathrm{mn}}^{2}\right) S(p) e^{-\gamma_{m n} L_{i}\left\{\begin{array}{l}
-\sinh \left(\gamma_{\mathrm{mn}} \mathrm{z}\right) \text { if } \mathrm{p} \text { even } \\
+\cosh \left(\gamma_{\mathrm{mn}} \mathrm{z}\right) \text { if p odd }
\end{array}\right\}} \cos \left\{\frac{n \pi}{2 b}(y\right. \\
& +b)\}
\end{aligned}
$$

$$
\text { When, } z_{1}=0: \quad H_{z}^{i n c}=-j \sin \left(\frac{\pi x}{2 a}\right) e^{-j \beta z}
$$


Where " $2 \mathrm{a}$ " is the guide width, " $2 \mathrm{t}$ " the slot/waveguide wall thickness, and

$$
\begin{aligned}
& H_{z}^{c a v}\left(M_{z}^{i}\right){ }_{\mathrm{M}}^{\mathrm{M}} \\
& =-\frac{\mathrm{j} \omega \varepsilon}{\mathrm{\kappa}^{2}} \sum_{\mathrm{p}=1}^{\infty} E_{p, z}^{i} \sum_{m=p=1}^{\infty}\left\{k^{2}-\left(\frac{m \pi}{2 L_{i}}\right)^{2}\right\} \sin \left\{\left(\frac{\mathrm{m} \pi}{\mathrm{L}_{\mathrm{i}}}\right)(z\right. \\
& \left.\left.+L_{i}\right)\right\} \cos \left\{\frac{n \pi}{2 W_{i}}\left(x+W_{i}\right)\right\} \frac{(-1)}{\Gamma_{m n}\left\{\sin 2 \Gamma_{m n}\right\}} \\
& \cdot\left\{\left(\begin{array}{cc}
\cos \left\{\Gamma_{m n}(y-t)\right\} \cos \left\{\Gamma_{m n}\left(y^{\prime}+t\right)\right\} y>y^{\prime} \\
\cos \left\{\Gamma_{m n}\left(y^{\prime}-t\right)\right\} \cos \left\{\Gamma_{m n}(y+t)\right\} y>y^{\prime}
\end{array}\right) \begin{array}{l}
\text { For } \mathrm{m}=\mathrm{p} \\
\text { and } \mathrm{n}=0
\end{array}\right. \\
& 0 \quad \text { Otherwise }
\end{aligned}
$$

The method of moments is applied to Galerkin's specialization $[22,23]$ to obtain $2 \mathrm{M}$ different equation from the boundary conditions to enable the determination of the $E_{p, z}^{i}$. The weighting functions $w_{q, z}^{i}(x, y, z)$ are defined as follows:

$$
\begin{aligned}
& w_{q, z}^{i}(x, y, z) \\
& =\left\{\begin{array}{cr}
\sin \left\{\frac{q \pi}{2 l}\left(z^{\prime}-W_{i}+L_{i}\right)\right\} \delta\left(y^{\prime}-b\right) & \text { on aperture " } i " \\
0 & \text { Elsewhere }
\end{array}\right.
\end{aligned}
$$

For all $\mathrm{q}(\mathrm{q}=1,2,3, \ldots \ldots \ldots \ldots, \mathrm{M})$ after taking moment of each of the terms in boundary conditions (14)-(17), with $w_{q, z}^{l}$, we obtained a set of simultaneous equation which upon solving the unknown basis coefficients. Here, we assume that the weighting function defines over a slot having a slot length " $2 \mathrm{~L}_{\mathrm{i}}$ ", slot width " $2 \mathrm{~W}_{\mathrm{i}}$ ". Where, " $\mathrm{d}$ " is the distance between the slots. The $(\mathrm{p}, \mathrm{q})^{\text {th }}$ element of the moment matrices can be derived as follows:

$$
\begin{aligned}
& \left\langle H_{z}^{i n c}, w_{q, Z}^{1}\right\rangle=j \frac{2 \pi W_{q}}{L} \sin \left(\frac{\pi x_{w}}{2 a}\right) \\
& \cdot \sin c\left(\frac{\pi W}{2 a}\right) e^{-j \beta z_{d}} \frac{\left\{\begin{array}{c}
\cos (\beta L) \text { for } q \text { odd } \\
j \sin (\beta L) \text { for } q \text { even }
\end{array}\right\}}{\left\{\beta^{2}-\left(\frac{q \pi}{2 L}\right)^{2}\right\}} \\
& \left\langle H_{z}^{\text {wav }}, w_{p, z}^{1}\right\rangle \\
& =\sum_{m=0}^{\infty} \sum_{n=0}^{\infty} \frac{j \epsilon_{m} \epsilon_{n} W^{2}}{2 \eta \kappa \gamma_{\mathrm{mn}}^{2} \mathrm{ab}} \frac{\cos (n \pi)}{1+S^{2}(p)} \cos ^{2}\left\{\frac { m \pi } { 2 a } \left(x_{w}\right.\right. \\
& +a)\} \sin c^{2}\left\{\frac{m \pi}{2 a} W\right\}\left[\left[\left\{k^{2}-\left(\frac{\mathrm{p} \pi}{2 L}\right)^{2}\right\} \delta_{\mathrm{pq}} \mathrm{L}\right]\right. \\
& +\left(\frac{2 S(p) S(q)\left(k^{2}+\gamma_{m n}{ }^{2}\right)}{\gamma_{m n}\left(1+S^{2}(q)\right)}\right) \\
& \left.\times\left\{e^{-\gamma_{m n}\left\{\begin{array}{cc}
-\sinh \left(\gamma_{m n} \mathrm{z}\right) & \text { if } \mathrm{p}, \mathrm{q} \text { both even } \\
+\cosh \left(\gamma_{\mathrm{mn}} \mathrm{z}\right) & \text { if } \mathrm{p}, \mathrm{q} \text { both odd } \\
0 & \text { otherwise }
\end{array}\right\}}\right\}\right\}
\end{aligned}
$$

$$
\begin{aligned}
& \left\langle H_{z}^{c a v}, w_{p, z}^{1}\right\rangle \\
& =-\frac{\mathrm{j} \omega \varepsilon \mathrm{LW}}{\mathrm{\kappa}^{2}} \sum_{\mathrm{p}=1}^{\mathrm{M}} E_{p, z}^{i} \sum_{m=p=1}^{\infty}\left\{k^{2}-\left(\frac{m \pi}{2 L_{i}}\right)^{2}\right\} \sin \left\{\left(\frac{\mathrm{m} \pi}{\mathrm{L}_{\mathrm{i}}}\right)(z\right. \\
& \left.\left.+L_{i}\right)\right\} \cos \left\{\frac{n \pi}{2 W_{i}}\left(x+W_{i}\right)\right\}\left\{\frac{(-1)}{\Gamma_{m n}\left\{\sin 2 \Gamma_{m n}\right\}}\right\} \\
& \times\left\{\begin{array}{lr}
\left.\left(\begin{array}{l}
\cos \left\{\Gamma_{m n}(y-t)\right\} \cos \left\{\Gamma_{m n}\left(y^{\prime}+t\right)\right\} y>y^{\prime} \\
\cos \left\{\Gamma_{m n}\left(y^{\prime}-t\right)\right\} \cos \left\{\Gamma_{m n}(y+t)\right\} y>y^{\prime}
\end{array}\right)\right|^{\mathrm{m}=\mathrm{p}=\mathrm{q}} \\
0 \quad & \text { Otherwise } \mathrm{n}=0
\end{array}\right.
\end{aligned}
$$

$$
\begin{aligned}
& \left.\left\langle H_{z}^{\text {ext }}\left(\mathrm{e}_{\mathrm{pz}}\right), w_{q, z}^{2}\right\rangle\right|_{\text {visible region }} \\
& =-\frac{16 W^{2} L^{2}}{\lambda^{2} \eta} \int_{\theta=0}^{2 \pi} \int_{\varphi=0}^{2 \pi}\left(1-\sin ^{2} \theta \cos ^{2} \phi\right) \\
& \times \operatorname{sinc} c^{2}(W k \sin \theta \sin \phi) \\
& \quad\left\{\begin{array}{c}
\sin ^{2}(L k \sin \theta \sin \phi) \text { for } p, q \text { both are even } \\
\cos ^{2}(L k \sin \theta \sin \phi) \text { for } p, q \text { both are even } \\
0 \quad \text { otherwise }
\end{array}\right\} \\
& \times \frac{\left(\begin{array}{c}
p \pi \\
2
\end{array} \frac{q \pi}{2}\left\{1-\left(\frac{2 L k \sin \theta \sin \phi}{p \pi}\right)\right\}\left\{1-\left(\frac{2 L k \sin \theta \sin \phi}{q \pi}\right)\right\}\right.}{\times(\sin \theta d \theta d \phi)}
\end{aligned}
$$

$\left.\left\langle H_{z}^{\text {ext }}\left(\mathrm{e}_{\mathrm{pz}}\right), w_{q, z}^{2}\right\rangle\right|_{\text {invisible region }}$
$=-\frac{16 W^{2} L^{2}}{\lambda^{2} \eta} \int_{\theta=0}^{\pi / 2} \int_{\varphi=0}^{2 \pi}\left(1-\cosh ^{2} \theta \cos ^{2} \phi\right)$

$\times \operatorname{sinc}^{2}(W k \cosh \theta \sin \phi)$

$\times\left[\frac{\left\{\begin{array}{c}\sin ^{2}(L k \cosh \theta \sin \phi) \text { for } p, q \text { both are even } \\ \cos ^{2}(L k \cosh \theta \sin \phi) \text { for } p, q \text { both are even } \\ 0\end{array}\right\}}{\frac{p \pi}{2} \frac{q \pi}{2}\left\{1-\left(\frac{2 L k \cosh \theta \sin \phi}{p \pi}\right)\right\}\left\{1-\left(\frac{2 L k \cosh \theta \sin \phi}{q \pi}\right)\right\}}\right]$

$\times((\cosh \theta) d \theta d \phi)$

Rewriting equation in the matrix form, for all $\mathrm{p}$ and $\mathrm{q}$ :

$$
\left[\begin{array}{ll}
{\left[Y_{11}\right]} & {\left[Y_{12}\right]} \\
{\left[Y_{21}\right]} & {\left[Y_{22}\right]}
\end{array}\right]\left\{\begin{array}{l}
\left\{E_{p, z}^{1}\right\} \\
\left.E_{p, z}^{2}\right\}
\end{array}\right\}=\left\{\begin{array}{c}
\left\{h_{z}^{\text {inc }}\right. \\
\{0\}
\end{array}\right\}
$$

Once the admittance matrix is calculated by equation (32) then easily calculated the impedance matrix because impedance matrix is the reciprocal of admittance matrix. After calculating impedance matrix, the reflection coefficient $\Gamma$ or $\mathrm{S}_{11}$ and Transmission coefficients $\mathrm{T}$ or $\mathrm{S}_{21}$ at $\mathrm{z}=0$ plane are obtained as [22]:

$$
\begin{aligned}
& \Gamma= \\
& \left.\qquad \frac{\pi^{2} W_{i}}{4 \mathrm{a}^{3} \mathrm{~b} \eta \kappa \beta^{2}} \sin \left(\frac{\pi x_{i}}{2 a}\right) \operatorname{sinc}\left(\frac{\pi W_{i}}{2 a}\right)\right) \times \\
& \\
& {\left[\sum_{p=1}^{M} E_{p, z}^{i} \frac{S(p)}{1+S^{2}(p)}\left[\begin{array}{c}
\mathrm{j} \sinh \left(\beta \mathrm{L}_{\mathrm{i}}\right) \text { if p even } \\
\cosh \left(\beta \mathrm{L}_{\mathrm{i}}\right) \text { if p odd }
\end{array}\right]\right.}
\end{aligned}
$$


$\mathrm{T}$

$$
\begin{aligned}
& =1+\left(\frac{\pi^{2} W_{i}}{4 \mathrm{a}^{3} \mathrm{~b} \eta \kappa \beta^{2}} \sin \left(\frac{\pi x_{i}}{2 a}\right) \operatorname{sinc}\left(\frac{\pi W_{i}}{2 a}\right)\right) \\
& \times\left[\sum_{p=1}^{M} E_{p, z}^{i} \frac{S(p)}{1+S^{2}(p)}\left[\begin{array}{c}
\mathrm{j} \sinh \left(\beta \mathrm{L}_{\mathrm{i}}\right) \text { if } \mathrm{p} \text { even } \\
\cosh \left(\beta \mathrm{L}_{\mathrm{i}}\right) \text { if } \mathrm{p} \text { odd }
\end{array}\right]\right.
\end{aligned}
$$

$$
\text { Where, } S(p)=\frac{p \pi}{\left(2 L_{i} \gamma_{m n}\right)}
$$

\section{NUMERICAL RESULT AND DISCUSSION}

On the pre basis of the problem formulation, MATLAB codes have written to compute the reflection coefficients and transmission coefficients of the different case structures and compared with HFSS simulated data in Figure 9 (a) and Figure 9 (b) over an entire X-band (i.e. $8.2 \mathrm{GHz} 12.4 \mathrm{GHz}$ ) operation. Figure 9 shows that excellent agreement between theoretical MCMT data and Ansoft HFSS simulated data to validate the proposed MCMT methodology. The result indicates that proposed methodology able to solve reflection and transmission coefficient for four different cases of longitudinal slots of same electrical lengths milled on two waveguides for series and shunt slot array planar antenna.

After validating the analysis, computed the total gain data over the range of $8.2 \mathrm{GHz} \sim 12.4 \mathrm{GHz}$ by the using Ansoft HFSS software when cut off frequency/ solution frequency is $10 \mathrm{GHz}$ for four different cases are shown in Figure 10. In this figure case-III and case-IV maintains a high gain (more than $5 \mathrm{~dB}$ ) in entire $\mathrm{X}$-band and total gain is reached up to $7.7 \mathrm{~dB}$ at $10 \mathrm{GHz}$ in both cases. However case-I and case-II does not maintain high gain in an entire X-band, but total gain is reached up to $12.5 \mathrm{~dB}$ at $10 \mathrm{GHz}$ frequency in both cases. In case-I total gain characteristics shown in Figure10 that at $8.2 \mathrm{GHz} 8.4 \mathrm{GHz}, \quad 8.8 \mathrm{GHz} 11.2 \mathrm{GHz}, \quad 11.7 \mathrm{GHz} 12.4 \mathrm{GHz}$ frequency band antenna is working because of this reason total gain considered more than $0 \mathrm{~dB}$. Therefore, we can say that case-I antenna is working in multiband in nature within the $\mathrm{X}$ - band. In case-II total gain graph characteristics show that at $\quad 8.2 \mathrm{GHz} \sim 9.1 \mathrm{GHz}, \quad 9.1 \mathrm{GHz} 10.8 \mathrm{GHz}$ and $11.1 \mathrm{GHz} \sim 12.4 \mathrm{GHz}$ frequency band antenna is working because of this reason total gain is more than $0 \mathrm{~dB}$. Therefore, we can say that case II antenna is performed as multiband in nature. In case-III total gain graph characteristic shows that at $8.2 \mathrm{GHz} \sim 12.4 \mathrm{GHz}$ frequency band antenna is working because of this reason total gain is more than $5 \mathrm{~dB}$ and maximum total gain is reached up to $8.2 \mathrm{~dB}$ at $9.14 \mathrm{GHz}$ frequency. Therefore, we can say that case-III antenna is also working in single band with the entire coverage of X-band. In case-IV total gain graph characteristic shows that at $8.2 \mathrm{GHz} 12.4 \mathrm{GHz}$ frequency band antenna is working because of this reason total gain is more than $5 \mathrm{~dB}$ and maximum total gain is reached up to $7.9 \mathrm{~dB}$ at $12.4 \mathrm{GHz}$ frequency. Therefore, we can say that case-IV antenna is also working in single band with the entire coverage of X-band.

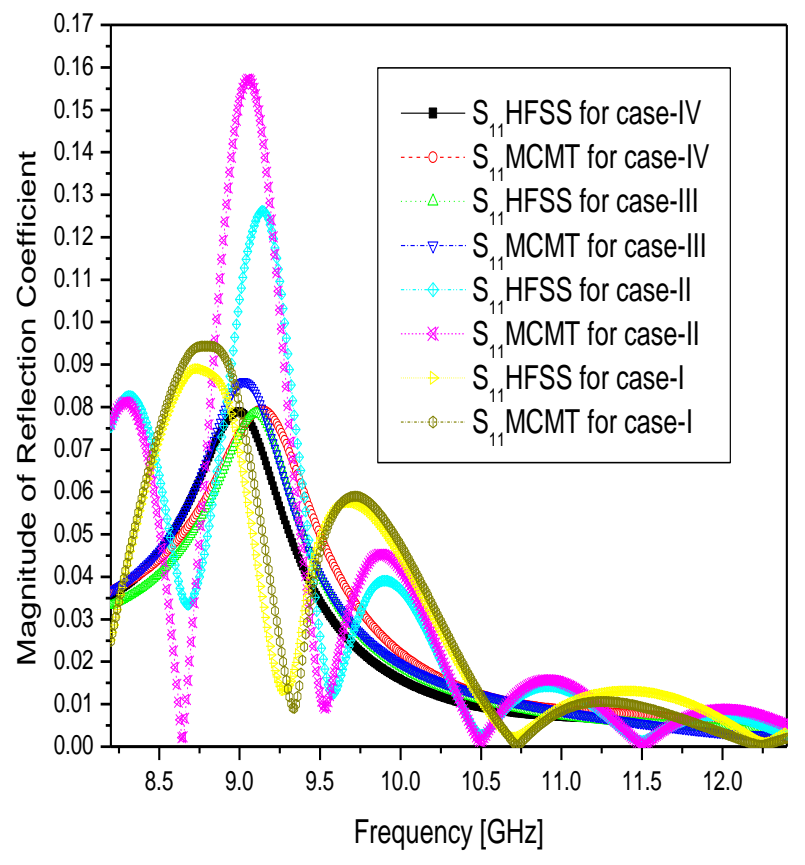

(a)

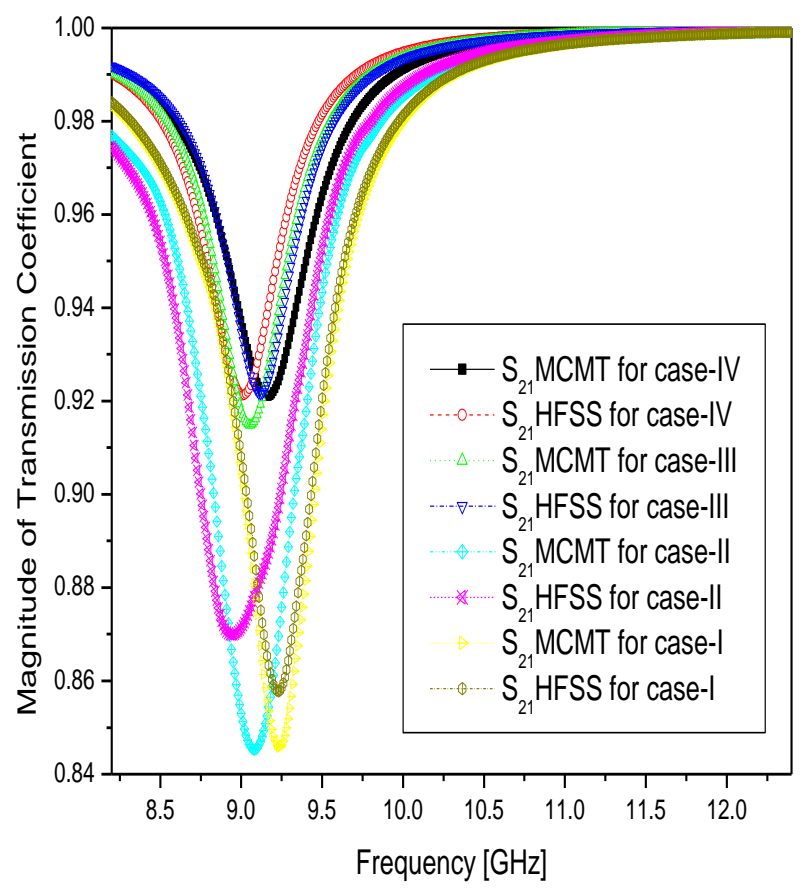

(b)

Figure 9: Theoretical and simulated (a) Magnitude of Reflection Coefficient (b) Magnitude of Transmission Coefficient of scattering parameter analysis of different cases of series and shunt slot array antenna in X-band frequency. 


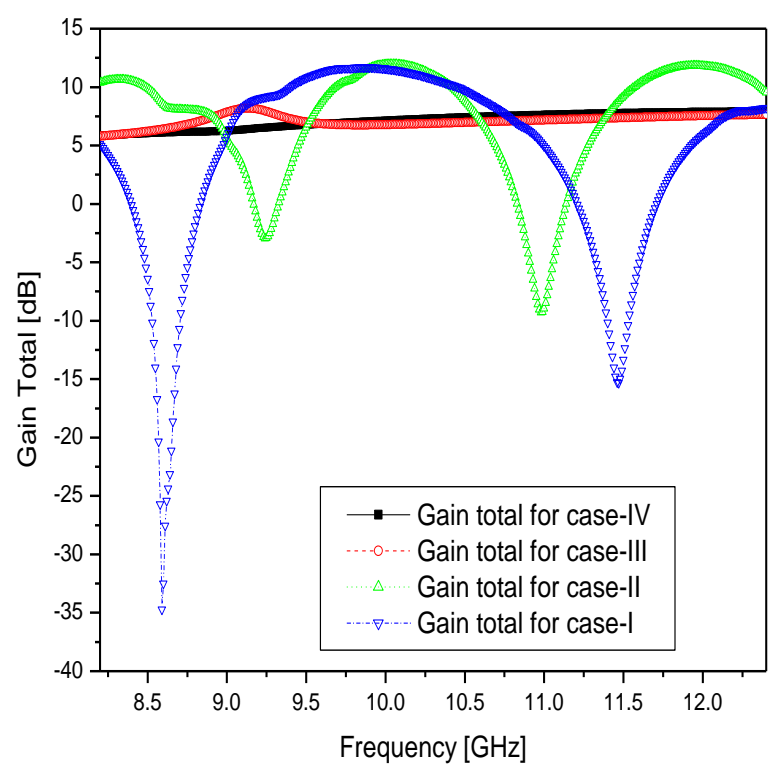

Figure 10 : Simulated total gain of different cases of two element series and shunt slot array planar antenna in X-band frequency.

\section{CONCLUSION}

This paper presents a study of scattering parameters two longitudinal slots of same electrical lengths milled on two waveguides for series and shunt slot array planar antenna. The methodology has been verified using Ansoft HFFS simulated data. The antenna provides gain high as $12.5 \mathrm{~dB}$ in both case-I and case-II, $8.2 \mathrm{~dB}$ in case-III, $7.9 \mathrm{~dB}$ in case-IV. The case-I and case-II antenna works in multiple band within in X-band. The case-III and case-IV antenna works in single band entire coverage of X-band. It could be noted that geometrical parameters (i.e. Length, width, position and offset of the slots) are not optimized. Here our aim was only to show that two longitudinal slots of same electrical lengths milled on two waveguides in series create multi-band and two longitudinal slots of same electrical lengths milled on two waveguides in shunt creates single band.

At last, the case-I and case-II is applicable for multi frequency selective device for communication while, the caseIII and case-IV is applicable for long distance data communication.

Conclusively, this paper indicates that two longitudinal slots of same electrical lengths waveguide shunt slot planar antenna behaves as a single band and two longitudinal slots of same electrical lengths waveguide series slot planar antenna behaves as a multiple band characteristics within X-band.

\section{ACKNOWLEDGMENT}

The research and software support provided by the Department of Electronics \& Communication Engineering, NIT, Jamshedpur, and Department of Electronics Engineering, ISM, Dhanbad is gratefully acknowledged respectively.

\section{REFERENCES}

[1] R. S. Elliot and L. A. Kurtz, "The Design of Small Slot Arrays", IEEE Transactions on Antennas and Propagation, Vol. 26, Issue - 2, Pp. $214-$ 219, 1978.

[2] R. S Elliott, "Improved Design Procedure for Small Arrays of Shunt Slots", IEEE Trans. Antennas Propagation, Vol. 31, Pp. 48-53, 1983.

[3] S. Gupta, "Electromagnetic Field estimation in Aperture and Slot Antennas with their Equivalent Network Representation", Ph.D. Dissertation, Department of Electronics \& Electrical Communication Engineering, I.I.T. Kharagpur, India, 1996.

[4] S. Edelberg and A. A. Oliner, "Mutual Coupling Effects in Large Antenna Arrays Part I Slot Arrays", IRE Transactions on Antennas and Propagation, Vol. 8, Issue - 3, Pp. 286 - 297, 1960.

[5] B. N. Das and G. S. Sanyal, "Mutual Impedance between two Resonant Slot Radiators", Proceedings of the Institution of Electrical Engineers, Vol. 118, Issue - 11, Pp. 1535 - 1538, 1971.

[6] R. S. Elliot, "On the Design of Travelling Wave Fed Longitudinal Shunt Slot Arrays", IEEE Transactions on Antennas and Propagation, Vol. 27, Issue - 5, Pp. $717-720,1979$.

[7] R. S. Elliot and W. R. O'Loughlin, "The Design of Slot Arrays, including Internal Mutual Coupling", IEEE Transactions on Antennas and Propagation, Vol. 34, Issue - 9, Pp. 1149 -1154, 1986.

[8] M. Grabowski, "Analysis of an Internal Mutual Couplings influence on a Radiation Pattern of a non Resonant Multi Slot Waveguide Array Antenna", IEEE Antenna and Propagation Society International Symposium, Vol. 24, Pp. 319 - 322, 1986.

[9] G. Mazzarella and G. Panareallo, "On the Evaluation of Mutual Coupling between Slots", IEEE Transactions on Antennas and Propagation, Vol. 35, Issue - 11, Pp. 1289 - 1293, 1987.

[10] S. R. Rengarajan and E. Gabrelian, "Efficient and Accurate Evaluation of External Mutual Coupling between Broad Wall Compound Slots", IEEE Transactions on Antennas and Propagation, Vol. 40, Issue - 6, Pp. $733-737,1992$.

[11] A. J. Sangstar and H. Wang, "Resonance Properties of Omnidirectional Slot Doublet in Rectangular Waveguide", Electronics Letters, Vol. 29, Issue -1, Pp. $16-18,1993$.

[12] A. J. Sangstar and H. Wang, "Moment Method Analysis of a Horizontally Polarized Omnidirectional Slot Antenna", IEE Proceedings on Microwaves, Antennas and Propagation, Vol. 142, Issue - 1, Pp. 1 6, 1995.

[13] A. Bastani and J. Rashed-Mohassed, "Analysis of Planar SlottedWaveguide Array Antennas with Longitudinal Slots using the Method of Moments", IEEE Antennas and Propagation Society International Symposium, Vol. 1, Pp.129-132, 2004.

[14] P. Mondal and A. Chakraborty, "Equivalent Circuit Representation of Waveguide Slot Doublet", National Symposium on Antennas and Propagation, Pp. 111 - 114, 2006.

[15] P. Mondal and A. Chakraborty, "Slotted Waveguide Antenna with two Radiation Nulls", IEEE Transactions on Antennas and Propagation, Vol. 56, Issue - 9, Pp. 3045 - 3049, 2008.

[16] Rintu Kumar Gyan and Sushrut Das, "Resonance and Parametric Analysis of Planar Broad-Wall Longitudinal Slot Array Antennas", Bonfring International Journal of Research in Communication Engineering, Vol. 2, No.3, Pp.13-20, 2012.

[17] Rintu Kumar Gyan and Sushrut Das, "A High-Gain Broad-Band Waveguide Longitudinal Slot Array Antenna," Progress in Electromagnetics Research C, Vol. 44, Pp.239-249, 2013.

[18] Hare Ram Jha and Shiva Nand Singh, "Design and Analysis of Waveguide-Fed Broad-Wall Longitudinal Log Periodic Slotted Array Antenna for $8.2 \sim 11.11 \mathrm{GHz}$ Frequency Applications", International Journal of Advanced Engineering Research and Science, Vol.1, Issue.6, Pp.15-24 Nov. 2014.

[19] Rintu Kumar Gyan and Sushrut Das, "Moment Method Analysis of Standard and Reduced Height Broad-Wall Longitudinal Slot Doublets in Rectangular Waveguides", International Journal of Electronics \& Communication Technology, Vol. 6, Issue 1, Spl- 1, Pp. 212-218, 2015.

[20] John D Kraus and Ronald J. Marhefka, "Slot, Patch and Horn Antenna", Antennas for all Application TMH $3^{\text {rd }}$ Edition, Pp-304, 2003.

[21] David M Pozar, "Microwave Engineering", John Wiley \& Sons (Asia) Pte Ltd, $2^{\text {nd }}$ Edition, Pp.-104, 1998.

[22] S. Das, "Analysis of Rectangular Waveguide Based Passive Devices and Antennas using Multiple Cavity Modeling Technique", PhD Dissertation, Department of Electronics \& Electrical Communication Engineering, I.I.T. Kharagpur, India, 2007. 
[23] R. F. Harrington, "Field Computation by Moment Methods", Roger E. Krieger Publishing Company, USA, Pp. 5 -7, 1993.

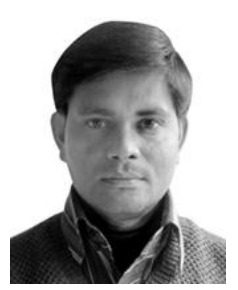

Hare Ram Jha was born in Bara Village, Saharsa District, Bihar, India, in 1980. He had completed his B.Sc. Engineering in Electronics \& Communication Engineering at the R. P. Sharma Institute of Technology, Patna, Bihar, India (affiliated to Magadh University, Bodh-Gaya, Bihar, India) in 2007. From 2007 to 2008 he was a Lecturer in Electronics \& Communication Engineering at the R. P. Sharma Institute of Technology, Patna, Bihar, India. After that, from 2009 to 2010 he was a Lecturer in Electronics \& Communication Engineering at the Ram Govind Institute of Technology, Koderma, Jharkhand, India. Then after from 2011 to 2014, he has been a lecturer in Electronics \& Communication Engineering Department at National Institute of Technology, Jamshedpur, and Jharkhand, India. Presently he is working as a Research Scholar at National Institute of Technology, Jamshedpur, Jharkhand, India.

In his area of specialization, he is interested in Electromagnetics, Microwave, Antenna and Wave Propagation. He has published one article in national conference and three articles in International Journal. (Email:hrjha.ece@nitjsr.ac.in)

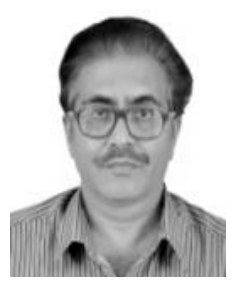

Shiva Nand Singh obtained his Bachelor of Technology degree in Electronics and Communication Engineering from BIT Mesra (a Deemed university), Ranchi, Jharkhand, India in 1980 and the M.Sc. Engineering degree in Electrical Engineering from Ranchi University, Jharkhand, India, in 1991. After that he had received $\mathrm{PhD}$ degree at the Department of electrical engineering, National Institute of Technology, Jamshedpur, Jharkhand, India.

He has published more than 50 papers in National and International journals based on his research work. He has been Co-ordinator of Govt. of India sponsored VLSI SMDP-II Project of National Institute of Technology, Jamshedpur, Jharkhand, India. Presently, he is the head of department of Electronics and Communication Engineering, National Institute of Technology, Jamshedpur, India. (E-mail:snsingh.ece@nitjsr.ac.in) 